\title{
I. THE SEPARATION OF SODIUM FROM POTASSIUM IN HUMAN BLOOD SERUM BY ION EXCHANGE CHROMATOGRAPHY
}

\author{
By WALTER L. ARONS AND A. K. SOLOMON
}

\author{
(From the Biophysical Laboratory and the Department of Medicine of the Harvard Medical \\ School and the Medical Service of the Peter Bent Brigham Hospital, Boston, Mass.)
}

(Submitted for publication February 8, 1954; accepted March 3, 1954)

The experiments to be described were undertaken to devise a simple and rapid technique for the separation of sodium from potassium in human blood serum in order to facilitate the simultaneous measurement of exchangeable sodium and potassium in man by the isotope dilution technique. This technique requires the intravenous administration of a known amount of radioactive sodium $\left(\mathrm{Na}^{24}\right)$ and radioactive potassium $\left(\mathrm{K}^{42}\right)$, followed by the determination, after a twenty-four hour equilibration period, of the individual sodium and potassium radioactivities and concentrations in the serum. The general principles underlying the application of the isotope dilution technique to the measurement of body constituents have been outlined by Edelman, Olney, James, Brooks, and Moore (1). The data presented here are primarily concerned with the separation of sodium from potassium in aqueous solutions and serum. The results of our measurements in man are presented in Part II of this study (2).

Since the isotope dilution method for the measurement of exchangeable body sodium and potassium requires separate determinations of the radioactivity of the $\mathrm{Na}^{24}$ and $\mathrm{K}^{42}$ found in the serum, three methods for making the discrimination between sodium and potassium were considered: 1 ) Physical separation, which makes use of differences in the physical characteristics of the radiation from the two isotopes; 2 ) chemical separation by precipitation; and 3 ) chemical separation by ion exchange.

It is difficult at present to make accurate individual measurements based on differences in physical properties of the radioactivity of $\mathrm{Na}^{24}$ and $\mathrm{K}^{12}$ in mixtures of the two isotopes, because their half-lives, 15.06 and 12.44 hours, respectively, are very similar, and because both isotopes emit beta particles and gamma rays whose energies are not markedly different. ${ }^{1}$

Chemical separation by precipitation can be carried out by a standard procedure, and James, Brooks, Edelman, and Moore (4) have developed a technique for adapting such a procedure to the requirements of the isotope dilution method. We have adopted chemical separation by ion exchange, making use of the sulfonic acid cation exchange resin, Dowex 50, in order to simplify the separation for clinical use. This procedure depends upon the greater affinity of Dowex $\mathbf{5 0}$ for the potassium ion than for the sodium ion so that these alkali metals may be eluted separately from the resin column with hydrochloric acid.

For our purposes the separation procedure had to satisfy the following special criteria: speed and completeness of separation, relative simplicity, and acceptable reproducibility. The importance of speed is apparent from the following facts. The amount of isotope that can be safely administered to man for investigative purposes is closely limited, and consequently our dose does not exceed 0.45 rep (roentgen equivalent physical). Approximately two half-lives elapse in the 24-hour period between injection and removal of the blood sample, with a resultant four-fold decrease in radioactivity. Furthermore, the amount of radioactivity in the $50 \mathrm{ml}$. sample of blood drawn represents but a small fraction of the amount injected. Thus, it is essential to reduce to a minimum the elapsed time between drawing the blood sample and measuring

1 The radiation from $\mathrm{Na}^{2}$ and $\mathrm{K}^{\mathrm{s}}$ is given by Hollander, Perlman, and Seaborg (3) as:

$\mathrm{Na}^{*} \beta, 1.39$ Mev. $(\sim 100 \%), 4.15$ Mev. $(0.003 \%)$; $\gamma, 1.38$ Mev. $(\sim 100 \%), 2.76$ Mev. $(\sim 100 \%)$ : $4.1 \mathrm{Mev}$. $(0.04 \%)$

$\mathrm{K}^{\mathrm{s}} \boldsymbol{\beta}^{\top}, 3.58 \mathrm{Mev}$. (75\%), 2.04 Mev. (25\%); $\gamma, 1.5 \mathrm{Mev}$. (25\%) 
the radioactivity in order to obtain a reasonable counting rate and accurate results.

The necessity for a complete separation arises from the disparate concentration of sodium and potassium in blood serum (143 $\mathrm{mEq}$. $\mathrm{Na}$ per $\mathrm{L}$. and $4.65 \mathrm{mEq}$. $\mathrm{K}$ per $\mathrm{L}$.). Although the initial injection is adjusted so that twice as much $\mathrm{K}^{42}$ as $\mathrm{Na}^{24}$ is administered, a contamination of the potassium by 1 per cent of the sodium would result in a 15 per cent error in the $\mathrm{K}^{\mathbf{4 2}}$ measurement. To obtain a cross-contamination of less than 1 per cent only 0.07 per cent of $\mathrm{Na}^{24}$ can be tolerated in the $\mathrm{K}^{\mathbf{4 2}}$ fraction.

Since Cohn and Kohn (5) first demonstrated that a sulfonated cation exchange resin, Dowex 50 , could be used to separate the alkali cations, a number of other investigators, Kayas (6), Beukenkamp and Rieman (7), and Sweet, Rieman, and Beukenkamp (8), have investigated the use of resins to separate sodium from potassium. None of the procedures developed by these workers fully satisfied the criteria we had formulated. The separations of Cohn and Kohn and Kayas required over 24 hours, while the method of Beukenkamp and Rieman required the use of a column almost $60 \mathrm{~cm}$. long, composed of colloidal Dowex 50, a mesh size which does not give reproducible results from batch to batch. Consequently, it was decided to determine by further studies with Dowex 50 the optimum combinations of such variables as mesh size, column length, cross linkage, normality of eluting acid, temperature, and rate of flow for our special needs.

\section{APPARATUS AND REAGENTS}

The resin was procured from the Dow Chemical Company 2 in the hydrogen cycle. To insure complete freedom of the resin from any small residual content of sodium and potassium, the resin was first eluted in column form with $300 \mathrm{ml}$. of $3 \mathrm{~N}$ hydrochloric acid at a rate of $1.5 \mathrm{ml}$. per minute. It was then washed with distilled water until the effluent was neutral to litmus paper. The resin columns rested on a glass wool plug or on a sintered glass filter (medium porosity) in a glass column of 1.3 to 1.6 $\mathrm{cm}$. diameter. The wet resin was poured into the column and allowed to settle to the desired height. A small loose plug of glass wool was then placed on top of the resin column.

$2 \mathrm{We}$ wish to express our appreciation to the Dow Chemical Co., Midland, Michigan, for their extremely helpful cooperation and for providing much of the resin used in these studies.

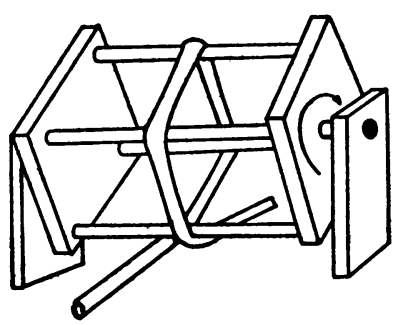

Fig. 1. Constant Flow Pump

The rubber tubing is pulled tightly over the four cross bars in the pump. Each of the cross bars can turn on its long axis as the pump rotates. The volume of eluate delivered is determined by the diameter of the rubber tubing and the speed with which the pump revolves. Four tubes can be wound around the pump in parallel to deliver at equal rates.

Hydrochloric acid (C.P.) was used as the eluting agent (elutriant). Samples were collected in the tubes of a fraction collector and the rate of flow was maintained at a constant speed with the aid of an electrically driven pump ${ }^{3}$ (Figure 1) introduced into the system between the column and the fraction collector. The pump consisted of four $0.6 \mathrm{~cm}$. round stainless steel bars spaced at equal intervals on a circle of $3.7 \mathrm{~cm}$. radius around a central shaft. Gum rubber tubing with an inside diameter of 2 to $3 \mathrm{~mm}$. was tightly wound around the steel cross-bars, which were themselves free to rotate around their long axes. As the pump rotated the fluid was propelled through the rubber tubing by the pressure of the bars.

Measurements of sodium and potassium concentration in the effluent were made with the use of the radioactive isotopes $\mathrm{Na}^{3}$ and $\mathrm{K}^{\mathrm{s}}$ obtained from the Atomic Energy Commission at the Brookhaven National Laboratory. The radioactivity was measured by use of a GeigerMueller dip counter described by Solomon and Estes (9) mounted in a special stand designed by Dr. C. V. Robinson to accommodate $8 \mathrm{ml}$. samples.

\section{EXPERIMENTAL PROCEDURE}

The test solution was an aqueous mixture of sodium chloride with a concentration of $140 \mathrm{mEq}$. per L. and potassium chloride with a concentration of $4.5 \mathrm{mEq}$. per $\mathrm{L}$. containing approximately $10^{6}$ counts per min. of $\mathrm{Na}^{*}$ and the same amount of $\mathrm{K}^{\mathrm{s}}$. These concentrations were chosen to simulate human serum concentrations. With our counting equipment and its background of 20 to 30 counts per minute we could easily obtain reliable measurements of activities of 100 counts per minute so that 0.01 per cent of the material added to the column could be detected.

Ten to forty $\mathrm{ml}$. of test solution were added to the resin column at rates up to $1.5 \mathrm{ml}$. per minute. Eight

${ }^{8} \mathrm{We}$ wish to express our appreciation to Ionics, Inc., Cambridge, Massachusetts, for their kindness in suggesting the use of such a pump and in making its design available to us. 
hundred ml. of eluting acid were then run through the column at rates varying from 0.74 to $1.1 \mathrm{ml}$. per min. and collected in $10 \mathrm{ml}$. fractions. The radioactivities of these fractions were measured in the dip counter. For this purpose one minute counts which gave probable errors of up to 5 per cent provided satisfactory accuracy. By calculating the per cent of added radioactivity in each of these tubes elution curves for $\mathrm{Na}^{3}$ and $\mathrm{K}^{\mathrm{a}}$ could be drawn.

Although the test solution was an aqueous one, equivalent results have also been obtained in the separation of sodium from potassium in serum. It was found experimentally that serum could not be added to the column directly without prior protein precipitation. For these experiments, $10^{\circ}$ counts per min. of $\mathrm{Na}^{24}$ and $\mathrm{K}^{\mathrm{s}}$ were added to $20 \mathrm{ml}$. of serum; the protein was then precipitated with $15 \mathrm{ml}$. of 10 per cent trichloracetic acid (C.P.), centrifuged at $1280 \mathrm{G}$ and washed with an additional 10 ml. of reagent. After the addition of the supernatant and the washings to the resin column, approximately 10 per cent of the added $\mathrm{Na}^{20}$ and $\mathrm{K}^{34}$ remained absorbed on the precipitate which was not a significant loss of radioactivity for counting purposes.

\section{RESULTS}

Dowex 50 mesh sizes, 200 to 400 , minus 325 (200 to 400 screened through a 325 mesh screen), minus 400, and colloidal agglomerates were investigated. Although the colloidal agglomerates theoretically (10) would provide the optimum mesh size for the separation, this resin size was not adopted since Sweet, Rieman, and Beukenkamp (8) had found the performance of colloidal agglomerates relatively non-reproducible from batch to batch. Consequently, we chose minus 325 mesh and, when it later became available, minus 400 mesh.

Figure 2 demonstrates the variation in the elution curves of sodium and potassium resulting from increasing the cross-linkage of the resin from 8 per cent to 12 per cent. Twelve per cent crosslinkage was determined to be the most favorable for our purpose.

The effect of varying the length of the resin column on the separation of the sodium and potassium ions is demonstrated in Table Ia. This table shows that an increase in length of the column by $0.5 \mathrm{~cm}$. under these conditions very effectively drew the $\mathrm{Na}^{24}$ and $\mathrm{K}^{42}$ peaks apart. While a long column assured a complete separation, it also increased

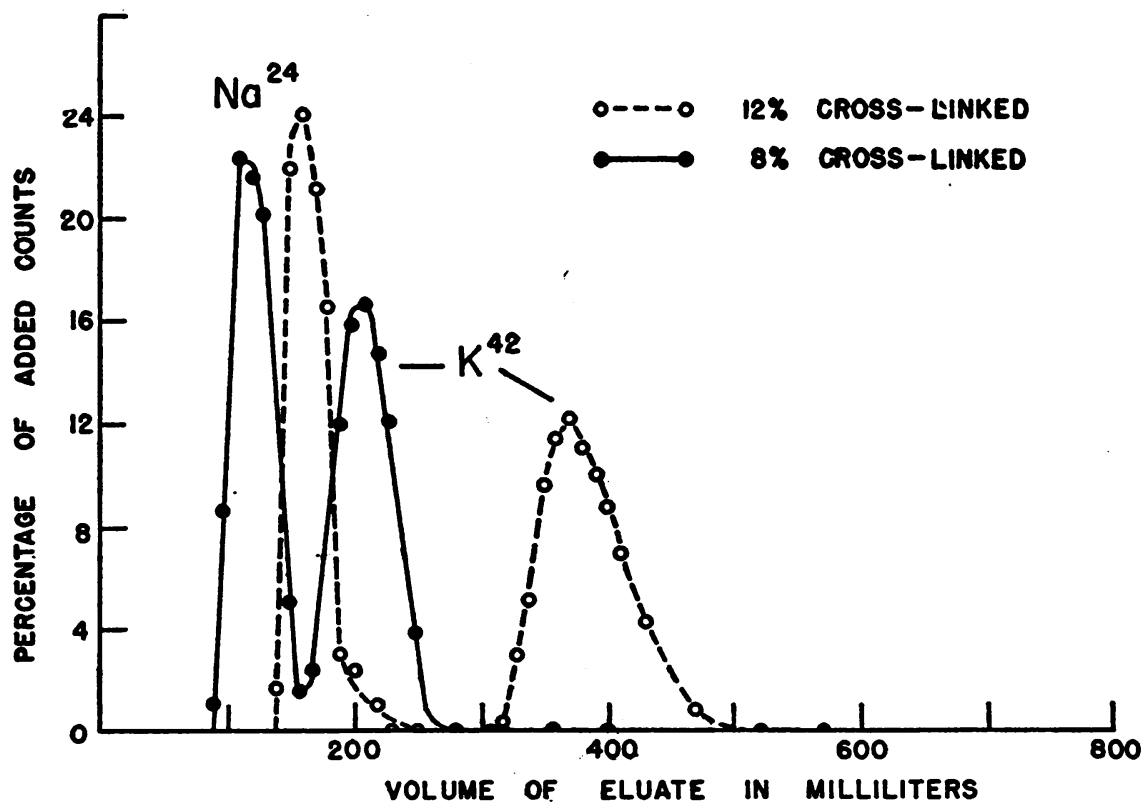

Fig. 2. Efrect of Cross-Lingage on Elution Curves of Sodium and Potassium

Exchanger-Dowex 50

Column $-5.5 \times 1.6 \mathrm{~cm}$.

Mesh-minus 325

Elutriant-0.26 N HCl

Flow rate $-0.74 \mathrm{ml} . / \mathrm{min}$.

Room temperature 
TABLE I

Effect of column length, elutriant concentration, and temperature on elution curves of sodium and potassium

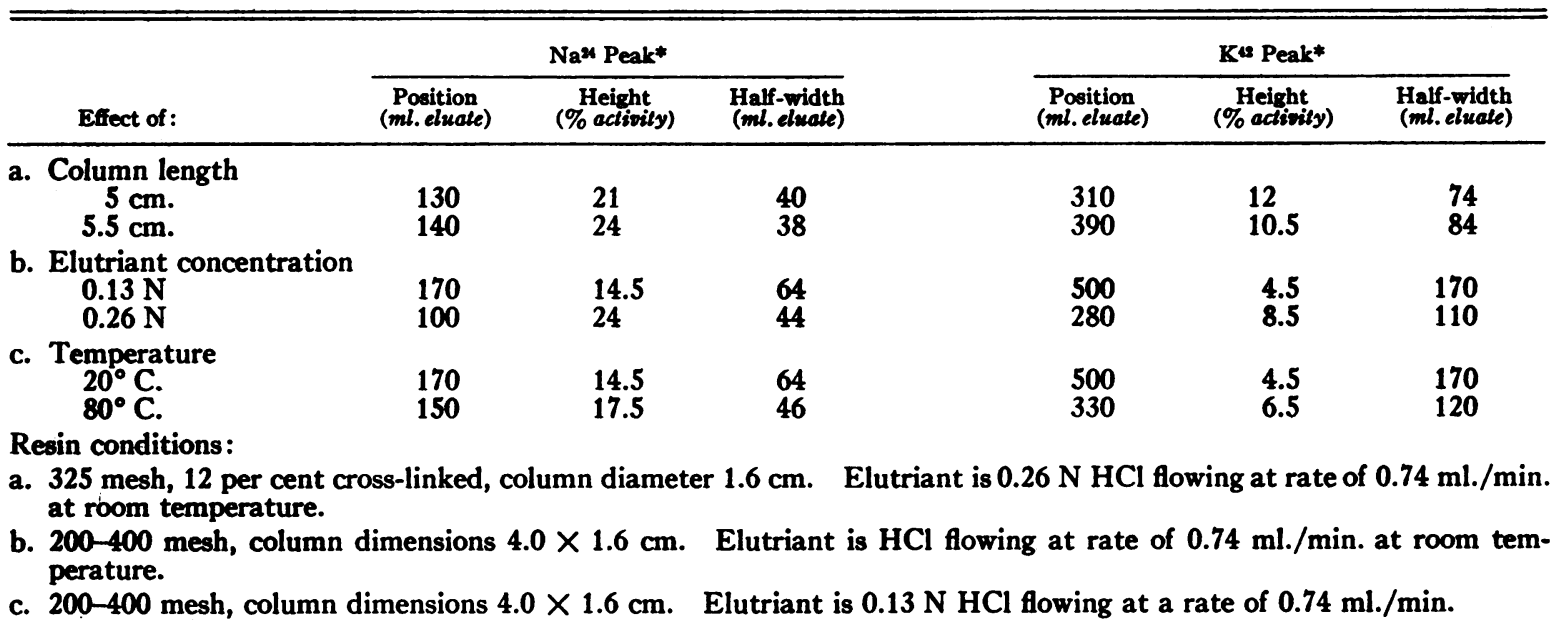

* The position of the $\mathrm{Na}^{24}$ and $\mathrm{K}^{*}$ peak is calculated in terms of $\mathrm{ml}$. of eluate. The peak height is expressed as per cent of added counts found in the tube containing the highest activity. The half-width of the peak, a measure of its sharpness, indicates the volume in $\mathrm{ml}$. of eluate across the peak at a point half-way to the top.

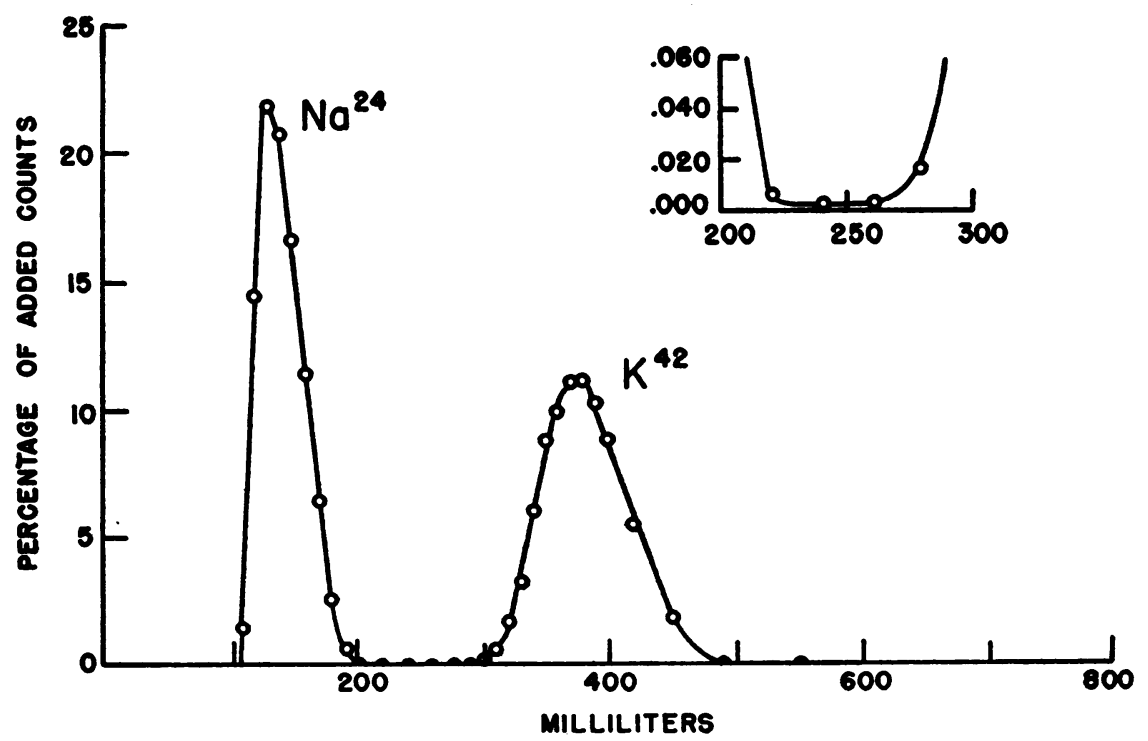

Fig. 3. Optimal Conditions for Resin Separation of Sodium from Potassium

$$
\begin{aligned}
& \text { Exchanger-Dowex } 50 \\
& \text { Column- } 8.0 \times 1.3 \mathrm{~cm} \text {. } \\
& \text { Mesh-minus } 400 \\
& \text { Flow rate- } 0.74 \mathrm{ml} . / \mathrm{min} \text {. } \\
& \text { Cross-linkage-12\% } \\
& \text { Room temperature }
\end{aligned}
$$

The insert which shows a 100 -fold magnification of the region between 200 and 300 milliliters indicates the negligible amount of cross-contamination in the valley between the peaks. These curves do not demonstrate the change in eluting acid normality and flow rate utilized to decrease the time for potassium elution. 
the time necessary to effect the separation. An $8.0 \mathrm{~cm}$. column was found to be the optimum length for our purpose.

The flow rate of eluting acid chosen was the fastest rate which would provide equilibrium conditions as judged from the symmetry of the peaks. An unimpaired flow was most easily achieved in systems which were kept constantly full of fluid to avoid the formation of air-locks. The optimal flow rate was found to be $0.74 \mathrm{ml}$. per min.

Increasing the normality of the eluting hydrochloric acid sharpened the peaks and hastened the appearance of the initial sodium peak. However, this advantage was limited by the fact that the potassium peak was moved closer to the sodium peak as the acid normality was increased. Table Ib shows the effect of changing the eluting acid from $0.13 \mathrm{~N}$ to $0.26 \mathrm{~N}$. The most desirable acid concentration was determined to be $0.26 \mathrm{~N}$ hydrochloric acid.

The effect of raising the temperature provided the same advantages and limiting factors as increasing the normality of the eluting acid in that as the peaks were sharpened the $\mathrm{K}^{\mathbf{}}$ peak moved closer to the $\mathrm{Na}^{24}$ peak. The temperature of the resin column was increased by wrapping resistance wire around the glass column above the resin so that the entrance temperature of the eluting acid was raised to $80^{\circ} \mathrm{C}$. The results of this temperature increase are shown in Table Ic. Since it was appreciably more difficult to operate at high temperatures than at room temperature this procedure was not adopted.

\section{OPTIMUM SEPARATION CONDITIONS}

Because of the numerous variables involved, approximately one hundred sets of elution curves were determined before the final conditions were chosen. The conditions for separation of sodium from potassium found to be optimal for our purposes were: a column of Dowex 50 resin of minus 400 mesh, 12 per cent cross-linked, $8.0 \mathrm{~cm}$. in length and $1.3 \mathrm{~cm}$. in diameter. The desirable eluting acid was $0.26 \mathrm{~N}$ hydrochloric acid with a flow rate of $0.74 \mathrm{ml}$. per min. Figure 3 shows the separation achieved under our optimum conditions; the insert indicates the negligible amount of crosscontamination between the two alkali ions. Be-

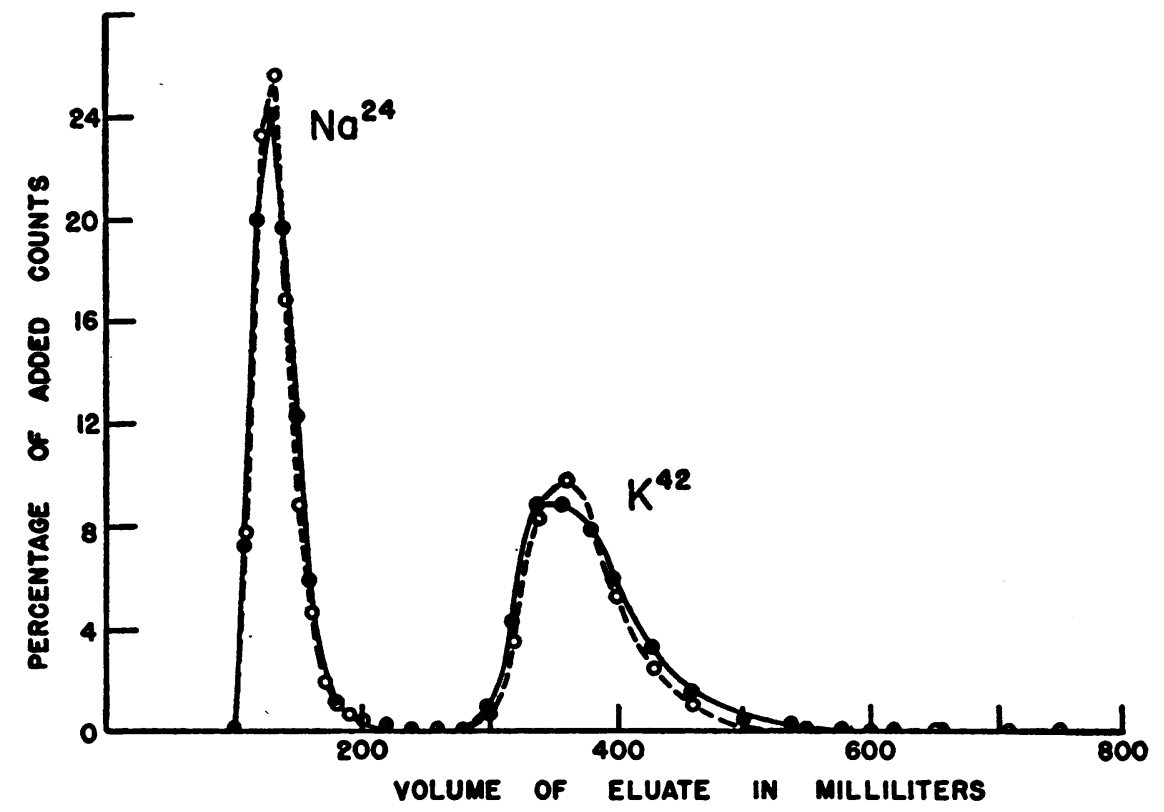

Fig. 4. Reproducrbirty of Elution Curves of Sodrum and Potassiux

Exchanger-Dowex 50

Column- $5.0 \times 1.6 \mathrm{~cm}$.

Mesh-minus 325

Flow rate $-0.74 \mathrm{ml} . / \mathrm{min}$.

Cross-linkage-12\% 
cause of the character of the individual curves which rise sharply from the baseline but tail off as they return, sodium may appear in the potassium fraction, whereas the reverse does not occur. The magnitude of the sodium contamination of the potassium fraction as determined by radioactivity measurements of $\mathrm{Na}^{24}$ in the potassium eluate is of the order of 0.008 per cent of the initial amount of sodium placed on the column, well within the permissible cross-contamination.

The excellent reproducibility of the elution curves in different columns with the same batch of resin is shown in Figure 4. Integration of the areas under the curves indicate that 96 to 100 per cent of the added activity is recovered in the eluate; these data represent complete recovery to the accuracy of these determinations.

The time necessary for the sodium fraction to be eluted from the column after the sodium and potassium have been added is approximately 3.5 hours. The first $80 \mathrm{ml}$. of eluate, including approximately $40 \mathrm{ml}$. of the supernatant fluid originally added to the column, is discarded since it contains no sodium or potassium. The sodium fraction is then collected in the following $120 \mathrm{ml}$. Another $60 \mathrm{ml}$. of eluting acid is then run through the column and discarded since it represents the valley between the peaks. The potassium fraction may then be recovered quickly in the next $80 \mathrm{ml}$. of effluent by doubling the speed of flow and increasing the normality of the eluting acid from $0.26 \mathrm{~N}$ to $2.6 \mathrm{~N}$. The total time for the separation and collection of the sodium and potassium fractions under these conditions is approximately six hours. Once the separation of sodium from potassium has been effected, the sodium and potassium eluate fractions are evaporated down to $10 \mathrm{ml}$. and each analyzed for electrolyte concentration and radioactivity. These measurements provide the necessary data for the calculation of exchangeable body sodium and potassium by the isotope dilation technique, as will be shown in Part II (2).

\section{SUMMARY}

A relatively rapid and efficient method for the separation of sodium and potassium in serum by ion-exchange chromatography has been presented.
Various factors affecting the separation of these alkali metals by this technique have been discussed and illustrative experimental data have been presented. The resin separation of sodium and potassium is to be utilized in the simultaneous measurement of exchangeable body sodium and potassium.

\section{ACKNOWLEDGMENTS}

We should like to express our thanks to Mr. Bradford D. Pearson for his assistance in making the radioactive analyses. This work has been supported in part by the Atomic Energy Commission and in part by the Medical Research and Development Board, Office of the Surgeon General, Department of the Army, under Contract No. DA-49-007-MD-135.

\section{REFERENCES}

1. Edelman, I. S., Olney, J. M., James, A. H., Brooks, L., and Moore, F. D., Body composition: Studies in the human being by the dilution principle. Science, 1952, 115, 447.

2. Arons, W. L., Vanderlinde, R. J., and Solomon, A. K., II. The simultaneous measurement of exchangeable body sodium and potassium utilizing ion exchange chromatography. J. Clin. Invest., 1954, 33, 1001.

3. Hollander, J. M., Perlman, I., and Seaborg, G. T., Table of isotopes. Revs. of Mod. Phys., 1953, 25, 469.

4. James, A. H., Brooks, L., Edelman, I. S., and Moore, F. D., Body sodium and potassium. I. The simultaneous measurement of exchangeable sodium and potassium in man by isotope dilution. Metabolism (In Press.)

5. Cohn, W. E., and Kohn, H. W., Ion-exchange separation of the alkali metals. J. Am. Chem. Soc., 1948, 70, 1986.

6. Kayas, G., Sur la Séparation du Sodium et du Potassium par les Echangeurs d'ions Organiques. Compt. rend. Acad. d. Sc., 1949, 228, 1002.

7. Beukenkamp, J., and Rieman, W., III, Determination of sodium and potassium, employing ion-exchange separation. Anal. Chem., 1950, 22, 582.

8. Sweet, R. C., Rieman, W., III, and Beukenkamp, J., Determination of alkali metals in insoluble silicates by ion-exchange chromatography. Anal. Chem., 1952, 24, 952.

9. Solomon, A. K., and Estes, H. D., The measurement of radioactivity in solution. Rev. Scient. Instruments, 1948, 19, 47.

10. Schubert, J., Applications of ion exchange to the separation of inorganic cations, in Nachod, F. C., Ion Exchange Theory and Application, New York, Academic Press, 1949, p. 167. 